\title{
Complete mitochondrial genome of the Japanese snapping shrimp Alpheus japonicus (Crustacea: Decapoda: Caridea): Gene rearrangement and phylogeny within Caridea
}

\author{
SHEN Xin ${ }^{1,2 *}$, LI Xiao ${ }^{3}$, SHA ZhongLi ${ }^{2}$, YAN BinLun $^{1} \&$ XU QiHua ${ }^{1}$ \\ ${ }^{1}$ Jiangsu Key Laboratory of Marine Biotechnology, Huaihai Institute of Technology, Lianyungang 222005, China; \\ ${ }^{2}$ Institute of Oceanology, Chinese Academy of Sciences, Qingdao 266071, China; \\ ${ }^{3}$ Shandong Peanut Research Institute, Qingdao 266100, China
}

Received February 21, 2012; accepted April 24, 2012

\begin{abstract}
The complete sequence of the mitochondrial genome of the Japanese snapping shrimp Alpheus japonicus Miers (Crustacea: Decapoda: Caridea) is presented here. A comparative analysis based on the currently available mitochondrial genomic data revealed many previously unknown characteristics of the mitochondrial genomes of caridean shrimps. The A. japonicus mitochondrial genome is $16487 \mathrm{bp}$ long and contains the typical set of 37 metazoan genes. The gene arrangements in the mitochondrial genomes of four previously studied carideans (Macrobrachium rosenbergii, M. nipponense, M. lanchesteri and Halocaridina rubra) were found to be identical to the pancrustacean ground pattern; thus, it was considered that gene rearrangements probably did not occur in the suborder Caridea. In the present study, a translocation of the trnE gene involving inversion was found in Alpheus mitochondrial genomes. This phenomenon has not been reported in any other crustacean mitochondrial genome that has been studied so far; however, the translocation of one transfer RNA gene (trnP or $\operatorname{trnT}$ ) was reported in the mitochondrial genome of Exopalaemon carinicauda. When the ratios of the nonsynonymous and synonymous substitutions rates $(\mathrm{Ka} / \mathrm{Ks})$ for the 13 protein coding genes from two Alpheus species (A. japonicus and A. distinguendus) and three Macrobrachium species (M. rosenbergii, M. nipponense, M. lanchesteri) were calculated, the Ka/Ks values for all the protein coding genes in Alpheus and Macrobrachium mitochondrial genomes were found to be less than 1 (between 0.0048 and 0.2057), indicating that a strong purification selection had occurred. The phylogenetic tree that was constructed based on the mitochondrial protein coding genes in the genomes of nine related species indicated that Palaemonidae and Alpheidae formed a monophyly and shared a statistically significant relationship, (Palaemonidae+Alpheidae)+Atyidae, at the family level.
\end{abstract}

Decapoda, Caridea, mitochondrial genome, gene order, phylogeny

Citation: Shen X, Li X, Sha Z L, et al. Complete mitochondrial genome of the Japanese snapping shrimp Alpheus japonicus (Crustacea: Decapoda: Caridea): Gene rearrangement and phylogeny within Caridea. Sci China Life Sci, 2012, 55: 591-598, doi: 10.1007/s11427-012-4348-1

With few exceptions, the mitochondrial DNA of Metazoa is circular, 11-20 kb in length, and encodes 37 genes: 13 protein coding genes (PCGs: coxl-3, cob, nadl-6, nad4L, atp6 and atp8), two ribosomal RNAs (rRNAs: srRNA and lrRNA), and 22 transfer RNAs (tRNAs) [1]. Complete mitochondrial genomes are potentially powerful tools that

*Corresponding author (email: shenthin@163.com) have been used to study the evolutionary history and phylogenetic relationships among metazoans [2]. Mitochondrial genomes also can provide important background information for molecular ecology and population genetics of related species. Caridea Dana, 1852 is one of the largest infraorders in the order Decapoda and is very common in marine and fresh waters. It contains many species of commercial interest. Alpheidae, which currently contains 46 
genera and about 600 valid species, is possibly the most diverse family of decapods [3]. However, only one complete mitochondrial genome from this caridean group ( $\mathrm{Al}$ pheus distinguendus) has been reported so far [4]. In this paper, we report the complete mitochondrial genome of the Japanese snapping shrimp Alpheus japonicus (Crustacea: Decapoda: Caridea). Based on the currently available data, the mitochondrial genomes of caridean shrimps have been fully characterized.

\section{Materials and methods}

\subsection{Sample collection and DNA extraction}

The A. japonicus specimens were obtained from Qingdao, China. The muscle tissue from the fresh specimens was excised and immediately preserved in $100 \%$ ethanol. Total genomic DNA was isolated using a DNeasy tissue kit (Qiagen) following the manufacturer's protocol and dissolved in TE buffer $\left(10 \mathrm{mmol} \mathrm{L}^{-1}\right.$ Tris- $\mathrm{HCl}, 1 \mathrm{mmol} \mathrm{L}{ }^{-1}$ EDTA, $\mathrm{pH}=8.0$ ).

\subsection{Long PCR amplification}

Partial sequences of the coxl and $c o b$ genes from the $A$. japonicus DNA were amplified by polymerase chain reaction (PCR) using the following primer pairs: LCO1490+ HCO2198 [5] for the coxl gene; and L10061-CYB + H10699-CYB [6,7] for the $c o b$ gene. The PCR products were purified using the Montage PCR Cleanup Kit (Millipore) and directly sequenced on a $3730 \times 1$ DNA Analyzer (ABI).

Based on the sequences that were obtained, long PCR primers were designed to amplify the entire A. japonicus mitochondrial genome in two fragments: cob-cox1-F (GCGACGATGATTCTTCTCAACCAA)+cob-cox1-R (GCAAATGGGAATAGGAAGTGAAAG); and cox1-cob-F(CAC-CCTGTGCCAACTCCACTTTCG)+cox1-cob-R (CTTTCACTTCCTATTCCCATTTGC). The PCR reactions were conducted in a Mastercycler gradient machine (Eppendorf AG Inc.) in a total volume of $25 \mu \mathrm{L}$, containing $15 \mu \mathrm{L}$ sterile distilled $\mathrm{H}_{2} \mathrm{O}, 2.5 \mu \mathrm{L} 10 \times \mathrm{LA}$ PCR buffer II $\left(\mathrm{Mg}^{2+}\right.$ plus, TaKaRa), $0.5 \mu \mathrm{L}$ dNTP $\left(10 \mathrm{mmol} \mathrm{L}{ }^{-1}\right.$ each, $0.2 \mathrm{mmol} \mathrm{L}^{-1}$ final concentration), $2 \mu \mathrm{L}$ each primer $\left(5 \mu \mathrm{mol} \mathrm{L}^{-1}\right), 1 \mu \mathrm{L}$ LA-Taq polymerase ( 1 unit, TaKaRa), and $2 \mu \mathrm{L}$ DNA template. The thermal cycling profile was as follows: initial denaturation at $94^{\circ} \mathrm{C}$ for 2 min followed by denaturation at $94^{\circ} \mathrm{C}$ for $20 \mathrm{~s}$, annealing at $54^{\circ} \mathrm{C}$ for $40 \mathrm{~s}$, and extension at $65^{\circ} \mathrm{C}$ for $8 \mathrm{~min}$, for 34 cycles. PCR products were purified using the Montage PCR Cleanup Kit (Millipore).

\subsection{Cloning and sequencing}

The two long PCR products that were obtained were broken into fragments ranging in size from 1 to $2 \mathrm{~kb}$ using re- striction endonuclease digestion and gel extraction. Then the DNA fragments were ligated into pUC19 plasmid vector. DNA sequence data were generated from single clones. Automated sequencing was performed on an $3730 \times 1$ DNA Analyzer (ABI).

\subsection{Gene identification and genome analyses}

Base calling was performed with phred and sequence reads were assembled in phrap with default parameters [8,9]. All assembled sequences were manually checked using CONSED to remove misassemblies [10]. Sequence annotation analysis was conducted with DOGMA [11] with the default settings and 13 PCGs and two rRNAs were initially identified. Gene predictions were subsequently refined by aligning the A. japonicus nucleotide or amino acid sequences that were obtained with the known mitochondrial genome sequences from other carideans. Most of the potential tRNA genes were identified using tRNAscan-SE 1.21 [12] in the default search mode with the invertebrate mitochondrial genetic code. The remaining tRNA genes were identified by inspecting the obtained sequences for tRNA-like secondary structures and anticodons. In addition, codon usage, synonymous and nonsynonymous substitutions in the 13 mitochondrial PCGs was estimated with DnaSP 5.10.01 [13].

\subsection{Phylogenetic analyses}

Phylogenetic analyses were performed using all the caridean mitochondrial genome sequences currently archived in GenBank (Macrobrachium rosenbergii, M. nipponense, M. lanchesteri, Halocaridina rubra, Exopalaemon carinicauda, and A. distinguendus) [4,14-16] along with the mitochondrial genome sequence of $A$. japonicus. The root was determined using the data from two penaeid shrimps ( $\mathrm{Li}$ topenaeus vannamei and Fenneropenaeus chinensis) [17] as the outgroup. Nucleotide sequences for the 13 PCGs from these mitochondrial genomes were aligned using ClustalW with the default settings [18] and the obtained sequences were concatenated into a single alignment. The final concatenated alignment of nucleotide sequences consisted of 11182 sites.

To determine the best fitting model, a nested likelihood ratio test was performed using ModelTest 3.7 [19]. After the evolutionary model was determined $(\mathrm{GTR}+\mathrm{I}+\mathrm{G})$, phylogenetic analyses were performed using PhyML 3.0 [20] and MrBayes 3.1 [21]. For the bootstrap probability of maximum likelihood (BPM) analyses, 1000 bootstraps were used to estimate the node reliability. For the Bayesian analyses, four chains of 1000000 generations were run with sampling every 1000 generations. The first 100000 generations being excluded from the analysis as "burn-in". After omitting the first 100 "burn in" trees, the remaining 900 sampled trees were used to estimate the $50 \%$ majority rule consensus tree 
and the Bayesian posterior probability (BPP).

\section{Results and discussion}

\subsection{Genome composition}

The A. japonicus mitochondrial genome is a circular molecule of $16487 \mathrm{bp}$ that encodes the typical set of 37 metazoan genes (13 PCGs, 22 tRNAs, and two rRNAs) (Figure 1). The positive and negative strands contain 22 and 15 genes, respectively. A total of $1758 \mathrm{bp}$ non-coding nucleotides were found, with $135 \mathrm{bp}$ in 17 intergenic regions and with a 1623 bp long non-coding region between the srRNA and trnI genes. We propose that this long non-coding region may be a putative control region because of its high $\mathrm{A}+\mathrm{T}$ content $(78.4 \%)$ and its conserved location in the mitochondrial genome of arthropods (Figure 1). The overall A+T content of the positive strand of the mitochondrial genome of $A$. japonicus was $64.9 \%(\mathrm{~A}=35.5 \% ; \mathrm{C}=22.8 \% ; \mathrm{G}=12.2 \%$; $\mathrm{T}=29.4 \%$ ); slightly higher than that of four of the studied carideans (M. rosenbergii, Halocaridina rubra, E. carinicauda, and $A$. distinguendus), but lower than that of two other carideans (M. nipponense and M. lanchesteri) (Table 1).

\subsection{Gene order}

Accumulating evidence has indicated that crustaceans and hexapods form a clade, usually referred to as Pancrustacea [22], and share the same ground pattern in mitochondrial gene order (pancrustacean ground pattern). It has been reported that the mitochondrial gene arrangements of four studied carideans ( $M$. rosenbergii, $M$. nipponense, $M$. lanchesteri and H. rubra) are identical to the pancrustacean ground pattern (Figure 2) and, therefore, it has been suggested that no gene rearrangement phenomena are present in the suborder Caridea [15,16]. However, we found that a translocation of the trnE gene involving inversion was present in the two Alpheus mitochondrial genomes (Figure 2). The translocation of this gene has not been reported in any of the other crustacean mitochondrial genomes studied so far; however, compared with pancrustacean ground pattern, the translocation of one tRNA gene (either trnP or trnT) has been found in the mitochondrial genome of E. carinicauda [14].

The 'duplication/random loss' mechanism is probably the most widely accepted hypothesis used to explain the translocation of genes in mitochondrial genomes. This mechanism involves the tandem duplication of gene regions as a result of slipped-strand mispairing during replication followed by the deletion of one of the duplicated regions [23]. Another hypothesis that has been proposed is the 'intramitochondrial recombination' mechanism which involves the specific breaking and re-joining of DNA double strands,

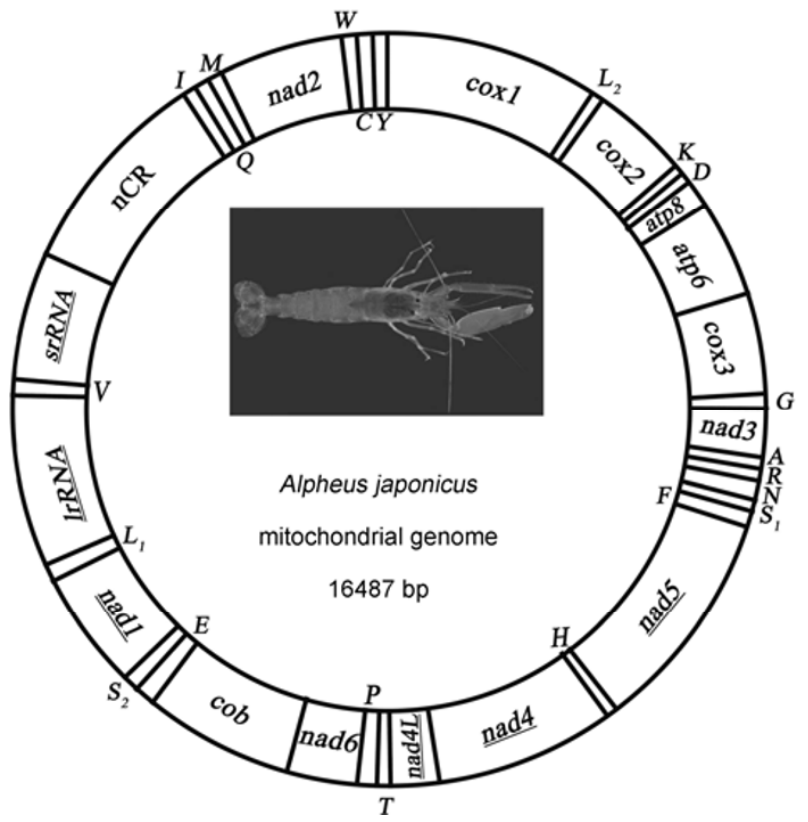

Figure 1 Gene map of the mitochondrial genome of the Japanese snapping shrimp Alpheus japonicus. Protein-coding genes are transcribed in a clockwise direction except for those that are underlined. The two rRNA genes are encoded on the negative strand. All tRNA genes are designated by single-letter amino acid codes except those encoding leucine and serine; $L_{1}, L_{2}, S_{1}$ and $S_{2}$ denote $t R N A^{\operatorname{Leu}(C U N)}, t R N A^{\operatorname{Leu}(U U R)}, t R N A^{\operatorname{Ser}(A G N)}$ and $t R N A^{\operatorname{Ser}(U C N)}$ genes, respectively. The 22 tRNA genes depicted on the outer and inner circles are encoded on the positive and negative strands, respectively.

Table 1 Characteristics of seven mitochondrial genomes from the infraorder Caridea

\begin{tabular}{|c|c|c|c|c|c|c|c|c|c|c|c|c|}
\hline \multirow[b]{2}{*}{ Species } & \multicolumn{2}{|c|}{ Heavy-strand } & \multicolumn{2}{|c|}{ Protein-coding genes } & \multicolumn{2}{|c|}{ lrRNA gene } & \multicolumn{2}{|c|}{ srRNA gene } & \multicolumn{2}{|c|}{ tRNA genes } & \multicolumn{2}{|c|}{$\mathrm{nCR}^{\mathrm{a})}$} \\
\hline & $\begin{array}{c}\text { Length } \\
\text { (bp) }\end{array}$ & $\begin{array}{l}\mathrm{A}+\mathrm{T} \\
(\%)\end{array}$ & $\begin{array}{c}\text { No. of } \\
\text { AA }\end{array}$ & $\begin{array}{l}\mathrm{A}+\mathrm{T} \\
(\%)\end{array}$ & $\begin{array}{c}\text { Length } \\
\text { (bp) }\end{array}$ & $\begin{array}{l}\mathrm{A}+\mathrm{T} \\
(\%)\end{array}$ & $\begin{array}{c}\text { Length } \\
\text { (bp) }\end{array}$ & $\begin{array}{l}A+T \\
(\%) \\
\end{array}$ & $\begin{array}{c}\text { Length } \\
\text { (bp) }\end{array}$ & $\begin{array}{l}A+T \\
(\%) \\
\end{array}$ & $\begin{array}{c}\text { Length } \\
\text { (bp) }\end{array}$ & $\begin{array}{l}\mathrm{A}+\mathrm{T} \\
(\%) \\
\end{array}$ \\
\hline A. distinguendus & 15700 & 60.2 & 3705 & 57.8 & 1299 & 64.8 & 872 & 60.3 & 1451 & 63.8 & 890 & 76.6 \\
\hline Macrobrachium rosenbergii & 15772 & 62.3 & 3708 & 60.1 & 1305 & 66.0 & 852 & 66.0 & 1449 & 64.7 & 931 & 75.7 \\
\hline M. nipponense & 15806 & 66.0 & 3698 & 64.2 & 1305 & 68.8 & 852 & 69.0 & 1450 & 65.7 & 950 & 79.9 \\
\hline Halocaridina rubra & 16065 & 63.2 & 3700 & 60.3 & 1351 & 68.2 & 872 & 68.8 & 1471 & 67.3 & 1020 & 78.4 \\
\hline Exopalaemon carinicauda & 15730 & 63.6 & 3696 & 60.5 & 1296 & 71.8 & 846 & 71.3 & 1445 & 65.8 & 886 & 79.7 \\
\hline
\end{tabular}

a) nCR, non-coding region. 


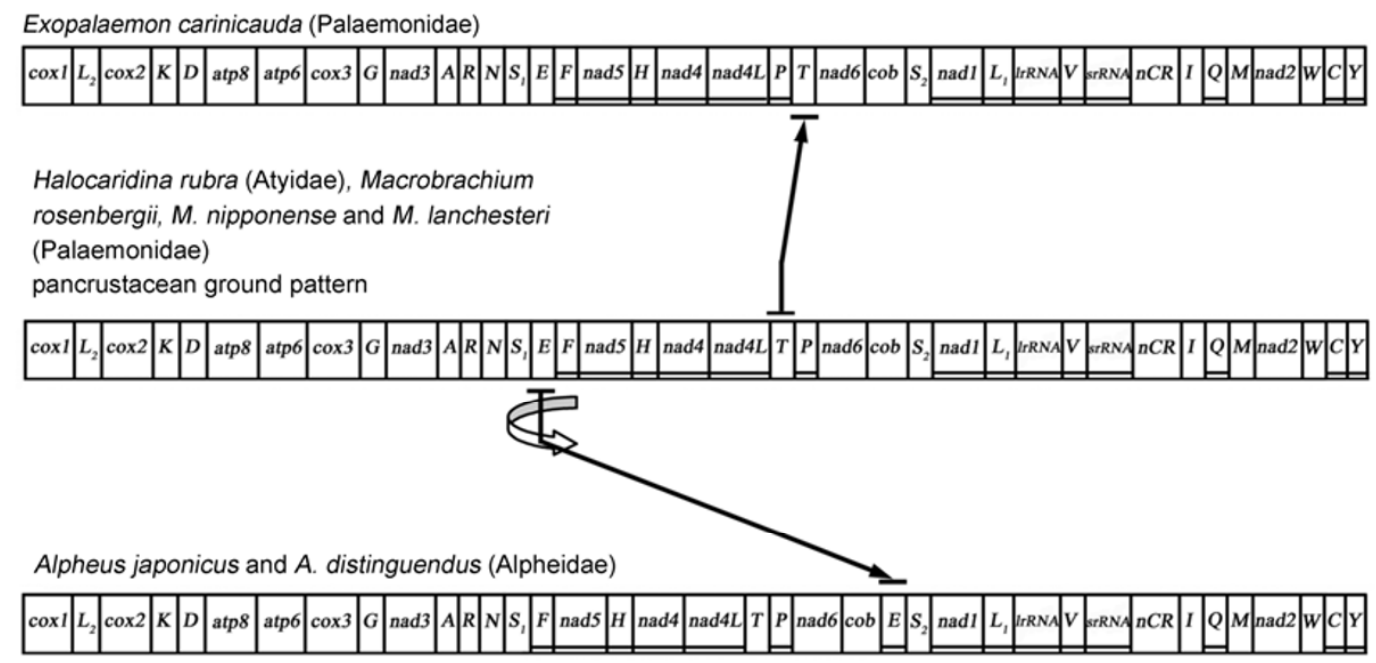

Figure 2 Linearized representation of the gene order arrangement in seven mitochondrial genomes from the infraorder Caridea. The arrows indicate the rearranged gene. The circling arrow indicates gene inversion. The genes that are encoded on the negative strand are underlined. The abbreviated tRNA gene names are defined in the legend to Figure 1.

thus promoting gene rearrangements and gene inversions [24]. We suggest that the latter mechanism may be the one that is responsible for translocation and inversion of the trnE gene in the Alpheus mitochondrial genomes, while, the former mechanism appears to be a plausible model for the translocation of the one tRNA gene $(\operatorname{trnP}$ or $\operatorname{trnT})$ in the mitochondrial genome of $E$. carinicauda. The different evolutionary mechanisms that are involved in mitochondrial gene rearrangements in related species are worthy of further study in the future.

\subsection{Protein-coding genes}

Nine of the 13 PCGs (cox1-3, cob, nad2-3, nad6, atp6 and atp8) are encoded on the positive strand, while the remaining four (nadl, nad4-5 and nad4L) are encoded on the negative strand (Figure 1). The typical metazoan initiation codon for transcription "ATN" is used in 11 (cox2-3, cob, nad2-6, nad4L, atp6 and atp8) of the 13 PCGs, while the coxl and nadl genes employ "TCG" and "GTG" as the start codons, respectively. The open-reading frames of 11 PCGs (cox2-3, cob, nad1-2, nad4-6, nad4L, atp6 and atp8) are terminated by the typical stop codon "TAA", while the remaining two genes (coxl and nad3) have an incomplete stop codon "T-".

\subsection{Base composition and codon usage}

The bias of the base composition of an individual strand is described as skewness and calculated as (A\%-T\%)/ $(\mathrm{A} \%+\mathrm{T} \%)$ and $(\mathrm{G} \%-\mathrm{C} \%) /(\mathrm{C} \%+\mathrm{G} \%)$ [25]. Except for the cox 2 and atp 8 genes which have a relatively weak AT skew of 0.073 and 0.093 , respectively, the other 11 PCGs have a definite AT skew between -0.047 and -0.379 (Table 2).
The majority of PCGs (cox1-3, cob, nad2-3, nad6, atp6 and atp8) have a strong GC skew between -0.155 and -0.552 , while nadl, nad4, nad4L, nad5, and the srRNA and IrRNA genes have a strong GC skew between 0.311 and 0.435 (Table 2).

The A. japonicus mitochondrial PCGs encode a total of 3709 amino acids. The most frequently occurring amino acid is Leu (15.39\%), followed by Ser $(9.81 \%)$, Phe $(8.22 \%)$ and Ile $(7.80 \%)$ (Table 3 ). A common feature in most metazoan genomes is the higher representation of nucleotides A and $\mathrm{T}$ which leads to a subsequent bias in the encoded amino acids. The overall A+T composition of the proteincoding regions of A. japonicus is $62.3 \%$ (Table 1 ); at the third codon position, it is $67.6 \%$.

\subsection{Synonymous and nonsynonymous substitutions}

To analyze the selection pressure on mitochondrial PCGs of the caridean species, the ratio of the nonsynonymous and synonymous substitutions rates $(K a / K s)$ for the 13 PCGs from the two Alpheus species (A. japonicus and A. distinguendus) and three Macrobrachium species (M. rosenbergii, $M$. nipponense, M. lanchesteri) was calculated. We found that the $K a / K s$ rate was much less than 1 (between 0.0048 and 0.2057 ), indicating a strong purification selection (Figure 3). In the 13 PCGs of the two Alpheus, the $K a / K s$ value was lowest for the coxl gene, followed by values for the cox3 and cob genes, indicating that these genes are under strong selection pressure and functional constraints. On the other hand, the $K a / K s$ value for the atp 8 gene was the highest, followed by the values for the nad6 and nad 2 genes, indicating that these three genes are under less selective pressure than the other mitochondrial PCGs. In the 13 PCGs of the three Macrobrachium, the Ka/Ks value was lowest for the coxl gene, followed by the values for the cob and 
Table 2 Nucleotide composition and skews in the mitochondrial protein-coding and ribosomal RNA genes of Alpheus japonicus

\begin{tabular}{|c|c|c|c|c|c|c|c|c|}
\hline \multirow{2}{*}{ Gene } & \multirow{2}{*}{$\begin{array}{c}\text { Length } \\
\text { (bp) }\end{array}$} & \multicolumn{4}{|c|}{ Proportion of nucleotides } & \multirow{2}{*}{$\mathrm{A}+\mathrm{T}(\%)$} & \multirow{2}{*}{ AT skew } & \multirow{2}{*}{ GC skew } \\
\hline & & A & $\mathrm{C}$ & G & $\mathrm{T}$ & & & \\
\hline atp6 & 675 & 0.298 & 0.24 & 0.123 & 0.339 & 63.7 & -0.065 & -0.322 \\
\hline atp 8 & 159 & 0.371 & 0.233 & 0.088 & 0.308 & 67.9 & 0.093 & -0.451 \\
\hline$c o b$ & 1137 & 0.278 & 0.255 & 0.149 & 0.318 & 59.6 & -0.068 & -0.264 \\
\hline $\operatorname{cox} 1$ & 1534 & 0.274 & 0.243 & 0.178 & 0.305 & 57.9 & -0.054 & -0.155 \\
\hline $\cos 2$ & 684 & 0.322 & 0.244 & 0.156 & 0.278 & 59.9 & 0.073 & -0.219 \\
\hline $\cos 3$ & 789 & 0.289 & 0.238 & 0.15 & 0.323 & 61.2 & -0.056 & -0.229 \\
\hline nadl & 948 & 0.208 & 0.13 & 0.247 & 0.416 & 62.3 & -0.333 & 0.311 \\
\hline $\operatorname{nad} 2$ & 999 & 0.293 & 0.28 & 0.104 & 0.322 & 61.6 & -0.047 & -0.458 \\
\hline nad3 & 352 & 0.307 & 0.23 & 0.119 & 0.344 & 65.1 & -0.057 & -0.317 \\
\hline nad4 & 1335 & 0.205 & 0.108 & 0.254 & 0.433 & 63.8 & -0.357 & 0.404 \\
\hline $\operatorname{nad} 4 L$ & 300 & 0.213 & 0.093 & 0.22 & 0.473 & 68.7 & -0.379 & 0.404 \\
\hline nad5 & 1701 & 0.233 & 0.116 & 0.225 & 0.426 & 65.9 & -0.292 & 0.321 \\
\hline nad6 & 516 & 0.298 & 0.275 & 0.079 & 0.347 & 64.5 & -0.075 & -0.552 \\
\hline srRNA & 867 & 0.288 & 0.103 & 0.235 & 0.374 & 66.2 & -0.129 & 0.392 \\
\hline lrRNA & 1302 & 0.306 & 0.088 & 0.224 & 0.381 & 68.7 & -0.108 & 0.435 \\
\hline
\end{tabular}

Table 3 Codon usage in the 13 mitochondrial protein coding genes of Alpheus japonicus

\begin{tabular}{|c|c|c|c|c|c|c|c|c|c|c|c|c|c|c|c|}
\hline $\begin{array}{c}\text { Amino } \\
\text { acid }\end{array}$ & Codon & Number & $\begin{array}{c}\text { Percentage } \\
(\%)\end{array}$ & $\begin{array}{l}\text { Amino } \\
\text { acid }\end{array}$ & Codon & Number & $\begin{array}{c}\text { Percentage } \\
(\%)\end{array}$ & $\begin{array}{c}\text { Amino } \\
\text { acid }\end{array}$ & Codon & Number ${ }^{\mathrm{F}}$ & $\begin{array}{c}\text { Percentage } \\
(\%)\end{array}$ & $\begin{array}{c}\text { Amino } \\
\text { acid }\end{array}$ & Codon & Number ${ }^{\mathrm{F}}$ & $\begin{array}{c}\text { Percentage } \\
(\%)\end{array}$ \\
\hline \multirow{2}{*}{ Phe } & UUU & 187 & 5.04 & \multirow{4}{*}{ Ser } & UCU & 98 & 2.64 & \multirow{2}{*}{ Tyr } & UAU & 89 & 2.40 & \multirow{2}{*}{ Cys } & UGU & 31 & 0.79 \\
\hline & UUC & 118 & 3.18 & & $\mathrm{UCC}$ & 38 & 1.02 & & UAC & 53 & 1.43 & & UGC & 10 & 0.26 \\
\hline \multirow{2}{*}{ Leu } & UUA & 216 & 5.82 & & UCA & 86 & 2.32 & \multirow{2}{*}{ End } & UAA & 11 & 0.30 & \multirow{2}{*}{ Trp } & UGA & 74 & 1.89 \\
\hline & UUG & 78 & 2.10 & & UCG & 16 & 0.43 & & UAG & 0 & 0.00 & & UGG & 20 & 0.51 \\
\hline \multirow{4}{*}{ Leu } & CUU & 92 & 2.48 & \multirow{4}{*}{ Pro } & $\mathrm{CCU}$ & 54 & 1.46 & \multirow{2}{*}{ His } & CAU & 31 & 0.84 & & CGU & 12 & 0.31 \\
\hline & CUC & 40 & 1.08 & & $\mathrm{CCC}$ & 49 & 1.32 & & CAC & 49 & 1.32 & Aro & CGC & 4 & 0.10 \\
\hline & CUA & 115 & 3.10 & & $\mathrm{CCA}$ & 38 & 1.02 & \multirow{2}{*}{ Gln } & CAA & 57 & 1.54 & & CGA & 35 & 0.90 \\
\hline & CUG & 30 & 0.81 & & CCG & 16 & 0.43 & & CAG & 17 & 0.46 & & CGG & 14 & 0.36 \\
\hline \multirow{2}{*}{ Ile } & AUU & 192 & 5.18 & & $\mathrm{ACU}$ & 73 & 1.97 & \multirow{2}{*}{ Asn } & AAU & 74 & 2.00 & \multirow{4}{*}{ Ser } & AGU & 39 & 1.00 \\
\hline & AUC & 97 & 2.62 & & $\mathrm{ACC}$ & 50 & 1.35 & & AAC & 55 & 1.48 & & AGC & 8 & 0.20 \\
\hline \multirow{2}{*}{ Met } & AUA & 152 & 4.10 & Inr & ACA & 67 & 1.81 & \multirow{2}{*}{ Lys } & AAA & 51 & 1.38 & & AGA & 59 & 1.51 \\
\hline & AUG & 43 & 1.16 & & ACG & 11 & 0.30 & & AAG & 33 & 0.89 & & AGG & 27 & 0.69 \\
\hline \multirow{4}{*}{ Val } & GUU & 106 & 2.86 & & GCU & 96 & 2.59 & \multirow{2}{*}{ Asp } & GAU & 43 & 1.16 & \multirow{4}{*}{ Gly } & GGU & 65 & 1.66 \\
\hline & GUC & 25 & 0.67 & $\Delta 1_{0}$ & GCC & 61 & 1.64 & & GAC & 31 & 0.84 & & GGC & 35 & 0.90 \\
\hline & GUA & 71 & 1.91 & Ald & GCA & 67 & 1.81 & \multirow{2}{*}{ Glu } & GAA & 48 & 1.29 & & GGA & 80 & 2.05 \\
\hline & GUG & 42 & 1.13 & & GCG & 16 & 0.43 & & GAG & 31 & 0.84 & & GGG & 83 & 2.12 \\
\hline
\end{tabular}

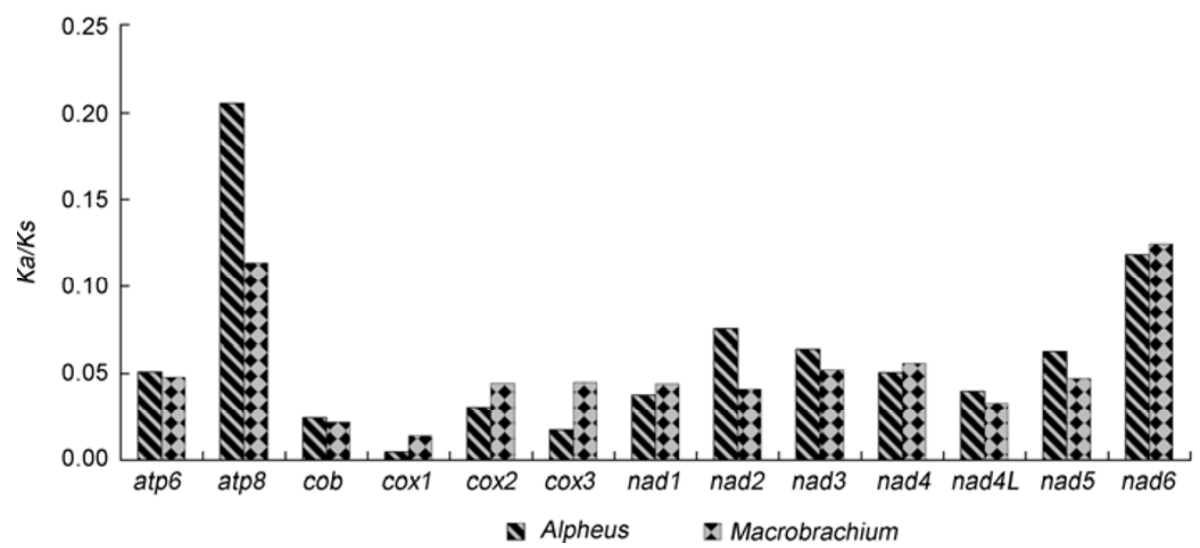

Figure 3 The ratios of the nonsynonymous and synonymous substitutions rates $(\mathrm{Ka} / \mathrm{Ks})$ in the protein coding genes of two Alpheus and three $\mathrm{Macrobra-}$ chium species. 
nad4L genes, indicating that these genes are under strong selective pressures and functional constraints; the $\mathrm{Ka} / \mathrm{Ks}$ value was highest for the nad6 gene, followed by the values for the atp 8 and nad4 genes, indicating that the selection pressure on these genes is weak.

\subsection{Transfer and ribosomal RNA genes}

The A. japonicus mitochondrial genome encodes 22 tRNA genes, each of which was predicted to fold into a clover-leaf secondary structure that is ranged in size from $63(\mathrm{trnH})$ to $71(\operatorname{trn} K)$ nucleotides. The DHU arm of the $\operatorname{trn} S_{1}$ gene lacked any secondary structure (Figure 4). The total length of the 22 tRNA genes in the A. japonicus mitochondrial genome is $1468 \mathrm{bp}$, which is longer than the majority of studied caridean mitochondrial genomes (1445-1451 bp) except for the mitochondrial genome of H. rubra (1471 bp).
The A+T content of the 22 tRNA genes in the A. japonicus mitochondrial genome was $65.2 \%$, which is similar to that of other carideans (Table 1).

The IrRNA gene lies between $\operatorname{trn} L_{l}$ and $\operatorname{trn} V$, while the srRNA gene lies between $\operatorname{trn} V$ and the putative control region. Both rRNA genes are encoded on the negative strand (Figure 1). The location and orientation of the rRNA genes are identical to the pancrustacean ground pattern (Figure 2). The lengths of the $\operatorname{lrRNA}$ and $s r R N A$ genes are 1302 and 867 bp and their A+T contents are $68.7 \%$ and $66.2 \%$, respectively (Table 1), similar to that of other studied carideans.

\subsection{Phylogenetic analyses}

Phylogenies based on either maximum likelihood or Bayesian analyses of the concatenated nucleotide sequences pro-

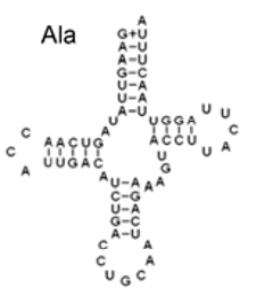

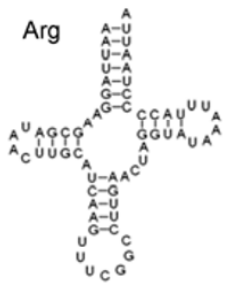

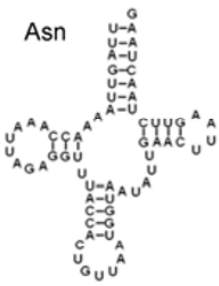

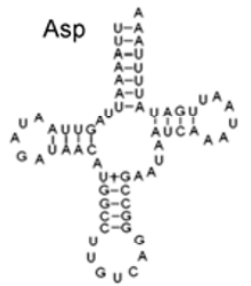



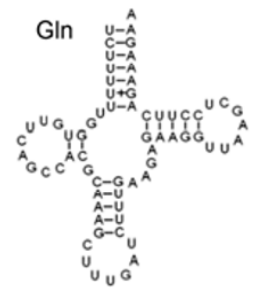

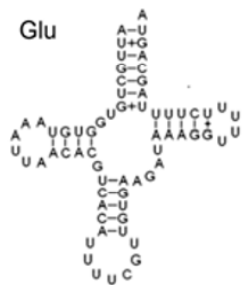



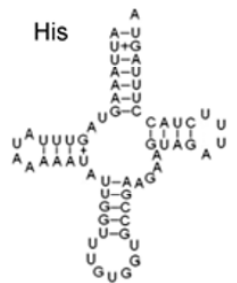

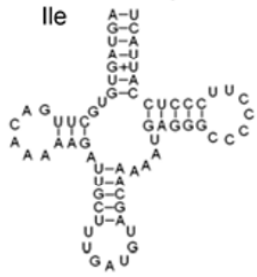

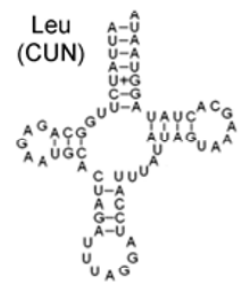

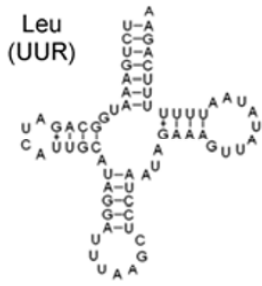

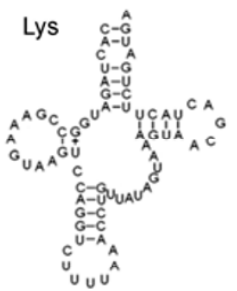

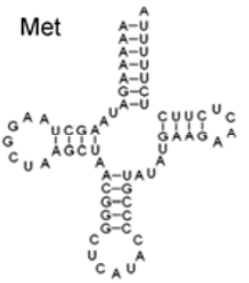

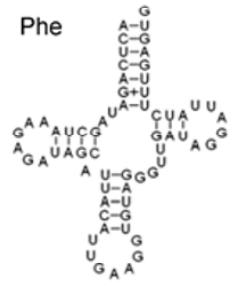

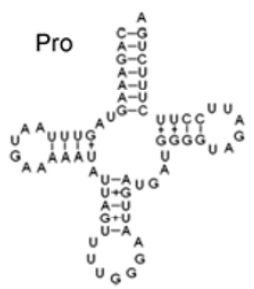

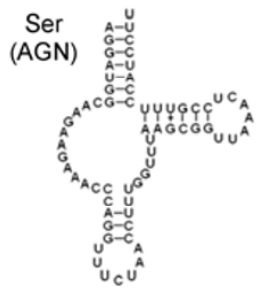

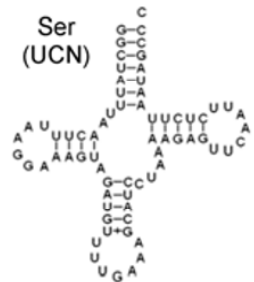

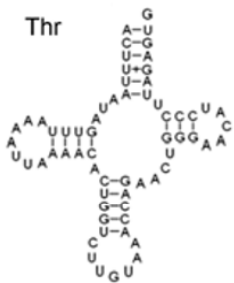

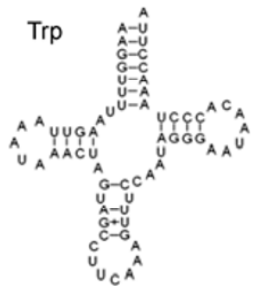

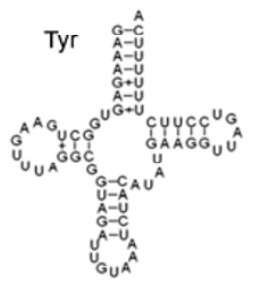

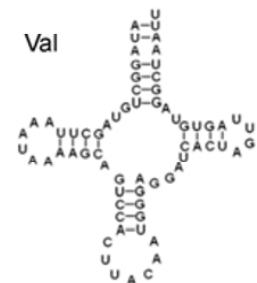

Figure 4 Predicted secondary structures of the 22 tRNA genes in the mitochondrial genome of Alpheus japonicus. 




Figure 5 Phylogenetic tree constructed from both the maximum likelihood and Bayesian (nucleotide acid data) analyses of 13 concatenated mitochondrial protein coding genes from nine mitochondrial genomes. The numbers at the nodes indicate the bootstrap values obtained from the maximum likelihood analysis (BPM) and Bayesian posterior probabilities (BPP), respectively. Black branches indicate the mitochondrial gene arrangements in these species were consistent with the pancrustacean ground pattern; gray branches indicate the mitochondrial genes in these species had undergone rearrangements.

duced identical trees (Figure 5). The phylogenetic tree based on the mitochondrial genomes indicated that Palaemonidae and Alpheidae formed a monophyly, and showed the statistically significant relationship (Palaemonidae+ Alpheidae $)+$ Atyidae at the family level $(\mathrm{BPM}=100, \mathrm{BPP}=$ 100) (Figure 5). The gene arrangements in the mitochondrial genomes of four studied carideans from the Palaemonidae (M. rosenbergii, $M$. nipponense and $M$. lanchesteri) and Atyidae (H. rubra) families are identical to the pancrustacean ground pattern; however, in three other carideans from the same families, Palaemonidae (E. carinicauda) and Alpheidae (A. japonicus and A. distinguendus), gene rearrangements were found (Figures 2 and 5). Our study also revealed a novel translocation involving inversion in the $A$. japonicus and $A$. distinguendus mitochondrial genomes compared with what has been observed in the mitochondrial genomes of the other crustaceans that have been studied so far. These data indicate that gene order is not conserved among caridean shrimps. As more mitochondrial data from this group become available, variations in gene order could be used to infer phylogenetic relationships within Caridea. Thus, more mitochondrial genome data should lead to a more comprehensive understanding of the phylogenetic relationships within Caridea, and between carideans and the other malacostracan crustaceans.

This work was supported by the National Natural Science Foundation of China (Grant Nos. 40906067 and 31172054), Special Funds From the Central Finance to Support the Development of Local Universities (Grant No. CXTD04), the China Postdoctoral Science Foundation Funded Project (Grant No. 2012M510054), the Jiangsu Key Laboratory of Marine Biotechnology (Grant Nos. 2009HS12 and 2009HS13) and the Qing Lan Project.
1 Boore J L. Animal mitochondrial genomes. Nucleic Acids Res, 1999, 27: 1767-1780

2 Shen X, Ma X Y, Ren J F, et al. A close phylogenetic relationship between Sipuncula and Annelida evidenced from the complete mitochondrial genome sequence of Phascolosoma esculenta. BMC Genomics, 2009, 10: 136

3 Williams S T, Knowlton N, Weigt L A, et al. Evidence for three major clades within the snapping shrimp genus Alpheus inferred from nuclear and mitochondrial gene sequence data. Mol Phylogenet Evol, 2001, 20: 375-389

4 Qian G, Zhao Q, Wang A, et al. Two new decapod (Crustacea, Malacostraca) complete mitochondrial genomes: bearings on the phylogenetic relationships within the Decapoda. Zool J Linn Soc, 2011, 162: 471-481

5 Folmer O, Black M, Hoeh W, et al. DNA primers for amplification of mitochondrial cytochrome $c$ oxidase subunit I from diverse metazoan invertebrates. Mol Marine Biol Biotechnol, 1994, 3: 294-299

6 Machida R J, Miya M U, Nishida M, et al. Complete mitochondrial DNA sequence of Tigriopus japonicus (Crustacea: Copepoda). Mar Biotechnol (NY), 2002, 4: 406-417

7 Yamauchi M, Miya M, Nishida M. Complete mitochondrial DNA sequence of the Japanese spiny lobster, Panulirus japonicus (Crustacea: Decapoda). Gene, 2002, 295: 89-96

8 Ewing B, Green P. Base-calling of automated sequencer traces using phred. II. Error probabilities. Genome Res, 1998, 8: 186-194

9 Ewing B, Hillier L, Wendl M C, et al. Base-calling of automated sequencer traces using phred. I. Accuracy assessment. Genome Res, 1998, 8: 175-185

10 Gordon D, Abajian C, Green P. Consed: a graphical tool for sequence finishing. Genome Res, 1998, 8: 195-202

11 Wyman S K, Jansen R K, Boore J L. Automatic annotation of organellar genomes with DOGMA. Bioinformatics, 2004, 20: 3252-3255

12 Schattner P, Brooks A N, Lowe T M. The tRNAscan-SE, snoscan and snoGPS web servers for the detection of tRNAs and snoRNAs. Nucleic Acids Res, 2005, 33: W686-689

13 Librado P, Rozas J. DnaSP v5: a software for comprehensive analysis of DNA polymorphism data. Bioinformatics, 2009, 25: 1451-1452

14 Shen X, Sun M A, Wu Z G, et al. The complete mitochondrial genome of the ridgetail white prawn Exopalaemon carinicauda Holthuis, 1950 (Crustacean: Decapoda: Palaemonidae) revealed a novel re- 
arrangement of tRNA genes. Gene, 2009, 437: 1-8

15 Ivey J L, Santos S R. The complete mitochondrial genome of the Hawaiian anchialine shrimp Halocaridina rubra Holthuis, 1963 (Crustacea: Decapoda: Atyidae). Gene, 2007, 394: 35-44

16 Miller A D, Murphy N P, Burridge C P, et al. Complete mitochondrial DNA sequences of the decapod crustaceans Pseudocarcinus gigas (Menippidae) and Macrobrachium rosenbergii (Palaemonidae). Mar Biotechnol, 2005, 7: 339-349

17 Shen X, Ren J F, Cui Z X, et al. The complete mitochondrial genomes of two common shrimps (Litopenaeus vannamei and Fenneropenaeus chinensis) and their phylogenomic considerations. Gene, 2007, 403: 98-109

18 Thompson J D, Gibson T J, Plewniak F, et al. The CLUSTAL_X windows interface: flexible strategies for multiple sequence alignment aided by quality analysis tools. Nucleic Acids Res, 1997, 25: 4876-4882

19 Posada D. ModelTest Server: a web-based tool for the statistical selection of models of nucleotide substitution online. Nucleic Acids Res, 2006, 34: W700-703
20 Guindon S, Dufayard J F, Lefort V, et al. New algorithms and methods to estimate maximum-likelihood phylogenies: assessing the performance of PhyML 3.0. Syst Biol, 2010, 59: 307-321

21 Ronquist F, Huelsenbeck J P. MrBayes 3: Bayesian phylogenetic inference under mixed models. Bioinformatics, 2003, 19: 1572-1574

22 von Reumont B M, Jenner R A, Wills M A, et al. Pancrustacean phylogeny in the light of new phylogenomic data: support for Remipedia as the possible sister group of Hexapoda. Mol Biol Evol, 2012, 29: 1031-1045

23 Boore J L. The duplication/random loss model for gene rearrangement exemplified by mitochondrial genomes of deuterostome animals. In: Sankoff D, Nadeau J H, eds. Comparative Genomics. Boston: Kluwer Academic, 2000. 133-216

24 Dowton M, Campbell N J. Intramitochondrial recombination-is it why some mitochondrial genes sleep around? Trends Ecol Evol, 2001, 16: 269-271

25 Perna N T, Kocher T D. Patterns of nucleotide composition at fourfold degenerate sites of animal mitochondrial genomes. J Mol Evol, 1995, 41: 353-358

Open Access This article is distributed under the terms of the Creative Commons Attribution License which permits any use, distribution, and reproduction in any medium, provided the original author(s) and source are credited. 